\title{
Identification of preferred combination of factors in manufacturing bioepoxy/clay nanocomposites
}

\author{
H. Salam ${ }^{\mathrm{a}, \mathrm{b}}$, Y. Dong ${ }^{\mathrm{a}}$, I. J. Davies ${ }^{\mathrm{a}}$ and A. Pramanik ${ }^{\mathrm{a}}$ \\ ${ }^{a}$ Department of Mechanical Engineering, School of Civil and Mechanical Engineering, \\ Curtin University, Perth, WA 6845, Australia \\ ${ }^{b}$ Department of Mechanical Engineering Education, Indonesia University of \\ Education, Bandung 40153, West Java, Indonesia \\ *Corresponding author. Email: Y.Dong@ curtin.edu.au
}

\begin{abstract}
The current study aims to identify the preferred combination of factors for manufacturing bioepoxy/clay nanocomposites based on epoxidised soybean oil (ESO), including material formulation and manufacturing parameters for maximising tensile strengths of nanocomposites according to Taguchi design of experiments (DoEs). A Taguchi mixed-level DoEs with an $L_{16}$ orthogonal array was selected. The response was set to achieve the maximum tensile strengths of nanocomposites with a preferred combination of factors determined by the Pareto analysis of variance (ANOVA). The associated results revealed that the ESO content was found to be the most significant factor with a contribution percentage of $66.63 \%$ amongst nine factors investigated. This result was followed by two less significant factors, namely mechanical mixing speed and clay content with contribution percentages of 19.09 and $7.01 \%$, respectively. However, other factors of clay type, curing agent type, mechanical mixing temperature and time, as well as sonication frequency and time, were categorised as non-significant factors from the manufacturing and economical point of view. A confirmation test was conducted based on the preferred combination of factors showing good agreement with statistically predicted results.
\end{abstract}

Keywords: bioepoxy/clay nanocomposites; Taguchi design of experiments (DoEs); mechanical properties; morphological structures 


\section{Introduction}

Two environmental issues have become increasingly important concerning petroleumbased epoxy resins [1,2]. The first one is related to the limitation of raw polymeric materials due to their reliance on the availability of fossil fuel stock. In response to this, it is necessary to find alternative polymeric materials from renewable resources that can replace petroleum-based epoxy resins. The second one is associated with the disposal of plastic wastes, which highlights the demand for alternative sources of nonpetroleum-based epoxy resins with improved biodegradability and costeffectiveness. In order to overcome those problems, plant oils such as those based on soybean, linseed, canola and palm have been investigated by many researchers as an alternative to conventional polymers [3-12]. Among these, soybean oil has been widely studied in the production of polymer composites due to its high contents of unsaturated fatty acid $[13,14]$. The chemical structure of soybean oil consists of a double carbon chain, in possession of a greater degree of oxirane rings with high iodine values when compared to other plant oils. The presence of oxirane rings is essential owing to their high reactivity as co-monomers when combined with other monomers to form crosslinked structures [15].

In particular, epoxidised soybean oil (ESO) has been used commercially as a coating material, lubricant, or plasticiser for poly(vinyl chloride) (PVC) [5,14,16-19]. Recently, the functionality of ESO in conventional polymers was found to improve the fracture toughness with increasing the ESO content. However, tensile strengths and glass transition temperature $T_{g}$ appeared to be worse than those of conventional polymers $[7,11,20-28]$. Nonetheless, previous research indicated that the properties of bioepoxy blends were inferior to those of petroleum-based epoxy resin $[29,30]$. In order to improve the properties of bioepoxy blends, good compatibility and reactivity between resins and curing agents are important in order to produce materials with a 
high crosslinking density $[8,17,18,27]$. Apparently, the improvement of bioepoxy properties based on plant oil still remains challenging. The further ESO investigation has been undertaken to elucidate the compatibility of ESO with petroleum-based epoxy resins [3-5,13,19,26,31-38]. Shabeer et al. [15] reported that the good compatibility of diglycidyl ether of bisphenol-A (DGEBA), ESO biopolymer blends and methylhexahydrophatalic anhydride (MHHPA) could result in the increase of $143 \%$ in fracture roughness for $75 \%$ biopolymers in blends. Moreover, Altuna et al. [39] stated that $40 \mathrm{wt} \%$ ESO/DGEBA blends cured with methyltetrahydrophatalic anhydride (MTHPA) yielded the impact strength to be $38 \%$ higher when compared with that of neat DGEBA resin despite the decrease in $T_{g}$ with increasing the ESO content.

In order to improve material properties and reduce application limitations, numerous studies showed that the addition of clays into polymer matrices was expected to improve mechanical and thermal properties of biopolymer/clay nanocomposites [23,31,40-47]. Liu and Erhan [31] investigated the effect of clay loading on tensile properties of ESO/clay nanocomposites, indicating significant increases in tensile strengths, moduli and elongation at break by 257, 203 and 19\%, respectively with the inclusion of $8 \mathrm{wt} \%$ Cloisite 30B clays when compared with those of ESO, which is associated with good clay wettability with the presence of intercalated structures. In addition, Tanrattanakul and Saithai [40] demonstrated that tensile strength, tensile modulus and elongation at break of bionanocomposites were enhanced by 118,255 and $2 \%$, respectively when embedded with 5 wt $\%$ clays. On the other hand, the investigation of biopolymer/clay nanocomposites was also undertaken to study the effect of clay fillers on tribological behaviour [41], thermal stability [43], biodegradability [46], flexural strength [48], impact strength [49], fracture toughness [32] and elongation at break [50] of bionanocomposites. In addition, the improvement of aforementioned properties of bionanocomposites was influenced by broadened clay 
interlayer spacing and improvement of clay wettability by means of the substitution of interlay cations of natural clay platelets $[42,51,52]$. On the other hand, Albayrak et al. [43] reported that clay exfoliated structures were obtained with the addition of 1 and 2 wt $\%$ organomodified clays in acrylated epoxidised soy bean oil (AESO) based biopolymer. More impressively, the storage modulus of corresponding bionanocomposites were enhanced by $400 \%$ as opposed to that of neat biopolymer.

Notwithstanding the effect of material combination in polymer/clay bionanocomposite systems, their mechanical properties can also be influenced by the wettability of clay fillers within matrices [52-56]. Amongst the pre-mixing processes for the fabrication of polymer/clay nanocomposites, the combination of mechanical shear mixing and sonication is commonly employed for the effective dispersion of clay fillers within polymer matrices $[8,12,45,46,57-60]$. In a mechanical shear mixing process, impeller and fluid shear forces are generally used to break up clay aggregates into fine clay particles. Atiemo-Obeng et al. [61] noted that operation methods, states and properties of solid and liquid phases, unit operation, impeller geometry and mixing parameters were key points for the effective dispersion during the solid-liquid mixing. Gupta et al. [62] introduced shear mixing process to facilitate the uniform dispersion of clay fillers within epoxy matrices, leading to exfoliated clay structures along with the improvement of tensile moduli of nanocomposites. Moreover, Park et al. [63] emphasised the importance of shear forces during shear mixing process to break up clay aggregates, and further improve clay wettability within polymer matrices. Besides, Alexandre and Dubois [51] stated that processing parameters including mixing speed, temperature and time, as well as impeller shear forces significantly affected the efficient manufacturing of polymer/clay nanocomposites. In addition, Consequently, shear mixing can be potentially used as the primary processing method for finely dispersing clay fillers into continuous matrices. 
On the other hand, the subsequent sonication method can be employed as a secondary step to disperse fine clay particles. Air bubbles produced from the sound wave propagation of ultrasonication could make polymer solutions easily penetrate into clay interlayer galleries, leading to an increase in clay interlayer spacing [64]. Ultrasonic parameters known to impact the clay wettability are frequency, power intensity, temperature, vapour and external pressures, viscosity and surface tension [65]. In line with this, Kaboorani et al. [64] found that sonication time and power intensity played an important role in dispersing fine particles within polymer matrices. The appropriate use of high power intensity (i.e., 100\%) could produce high-quality clay dispersion in less than 20 min. Moreover, Dean et al. [66] highlighted that the combination of ultrasonic and shear mixing techniques tended to improve clay wettability compared to shear mixing alone. Furthermore, Lam et al. [67] investigated the effect of ultrasonication time on mechanical properties of nanocomposite materials. The optimal mechanical properties could be achieved by using the ultrasonication process for approximately $10 \mathrm{~min}$. Moreover, it was noted that clay wettability and exfoliated structures could not be achieved if solely depending on ultrasonication. As a result, it is essential to combine shear mixing and ultrasonication for the best processing outcome in clay wettability. Considering two important aspects in manufacturing polymer/clay nanocomposites, namely material formulation and material processing parameters, it is critical to determine their preferred conditions as the guidance to achieve high-quality bioepoxy/clay nanocomposites with superior mechanical properties.

In light of previous research mentioned earlier, current study aims to identify a preferred combination of factors on manufacturing bioepoxy/clay nanocomposites using Taguchi design of experiments (DoEs) in response to the maximisation of their tensile strength. A commercial DGEBA resin was replaced with ESO at three different 
contents of 20,60 and $80 \mathrm{wt} \%$. These bioepoxy blends were mixed with four different types of clays, namely Cloisite $\mathrm{Na}^{+}$, Cloisite $10 \mathrm{~A}$, Cloisite 15 and Cloisite $93 \mathrm{~A}$ at the clay loading from 1 to $8 \mathrm{wt} \%$ and cured with two different curing agents, including isophorone diamine (IPDA) and methyltetrahydrophthalic anhydride (MTHPA). Since processing parameters are known to influence mechanical properties of resulting bioepoxy/clay nanocomposites, the variation of processing parameters in relation to mechanical mixing and ultrasonication were also selected, such as mechanical mixing speed, temperature and time, as well as sonication frequency and time. A solution casting method was used to fabricate bioepoxy/clay nanocomposites and their tensile strength was considered as a target response in DoEs, resulting in a preferred combination of factors in terms of material formulation and processing parameters. The DoE results were evaluated by the analysis of variance (ANOVA) technique to determine such a preferred combination of factors with the further validation made by confirmation tests.

\section{Experimental}

\subsection{Materials}

As-received commercial DGEBA epoxy resin with the epoxide equivalent weight (EEW) of 190-195 g.equiv ${ }^{-1}$ and isophorone diamine (IPDA) curing agent at ambient temperature were supplied by Adhesive Engineering Pty, NSW Australia, which were denoted as L13 Part A and Part B, respectively. The other curing agent methyltetrahydrophatalic anhydride (MTHPA), branded as Lindride 6, was purchased from Lindau Chemical, Inc., Columbia, USA. MTHPA was also blended with benzyltriethylammonium chloride as a latent thermal catalyst of quaternary ammonium

salt. As recommended by material suppliers, the mix ratio of DGEBA resin with IPDA and MTHPA was 30 and 85 phr, respectively. Meanwhile, ESO as bio-renewable 
monomers used to substitute for commercial epoxy resin in pre-designed material compositions, was purchased from Zhejiang Jiaao Enprotech Stock Co., Ltd., Zhejiang China. Four different types of montmorillonite (MMT) clay fillers, referred to as pristine clays Cloisite $\mathrm{Na}^{+}\left(\mathrm{CNa}^{+}\right)$, and three organomodified clays Cloisite 10A (C10A, Cloisite 15 (C15) and Cloisite 93A (C93A) were obtained from BYK-Chemie GmbH, Germany.

\subsection{Experimental method}

\subsubsection{Taguchi method}

Taguchi DoE is a robust design method using an experimental design to optimise product quality and manufacturing processes with a minimal variation of quality and reduced development and cost. To achieve optimal product quality, Taguchi method comprises three steps of product design, namely system design, parameter design and tolerance design [68]. The key point of system design is to determine functional factors or parameters influencing the target of product/process quality. As mentioned earlier, there are generally two categories of factors to influence the fabrication of bioepoxy/clay nanocomposites in this study, including material formulation and processing parameters. The second step is to define the factor levels and minimise noise factors that can affect the variation of product quality or characteristics. Finally, tolerance design can employ higher levels of factor design by manipulating the process condition and source of variability in order to improve product quality. The associated combination of functional factors and levels is listed in Table 1. The variation of factors and levels was set up based on previous research literatures, including ESO content $[8,12,15,27,33,38,39,40,43,69]$, clay type $[42,48]$, clay content $[41,49,70,71]$, curing agent type $[8,17,18,36]$, mechanical mixing parameters $[52,54,57,58,61-63,72]$ and ultrasonication parameters $[45,59,64,66,67,72]$. The benefit of using Taguchi 
method lies in the significant reduction in the number of required experimental trials compared to conventional full factorial DoEs, resulting in predicted outcomes at an acceptable level [68].

In this study, to identify the preferred combination of factors in relation to material formulation and processing parameters on tensile properties of bioepoxy/clay nanocomposites, Taguchi mixed-level DoEs with an $L_{16}$ orthogonal array was selected with each factor comprising two or four levels for the design option, as shown in Table 1. The explicit 16 random DoE layout trials is clearly indicated in Table 2. The number of such trials is much less than full factorial counterparts (i.e., 4096 trials). The response of DoE trials (i.e., tensile strength of bioepoxy/clay composites) was evaluated via a signal to noise $(S / N)$ ratio analysis. Moreover, $S / N$ ratio was also chosen to determine the preferred combination of factors, which is based on the fact that mathematically larger $\mathrm{S} / \mathrm{N}$ ratios generally lead to a better experimental response to achieve excellent mechanical properties together with additional technical and economical consideration [68]. The $S / N$ ratios are expressed in the unit of decibels (dB). The "larger-the-better" characteristic was used in this study to evaluate the target response with the $S / N$ function given by the following equation:

$$
S / N=-10 \log \left[\frac{1}{n} \sum_{i=1}^{n} \frac{1}{y_{i}^{2}}\right]
$$

where $S / N$ is the signal to noise ratio, $n$ is the number of measurements at each trial and $y$ is the target response [73].

\subsubsection{Pareto analysis of variance (ANOVA)}

Pareto ANOVA is a powerful technique to determine significant factors and preferred combination of factors in Taguchi DoEs. Significant factors in terms of material 
formulation and processing were determined according to the cumulative contribution percentage over $90 \%$. The rest of factors were categorised as non-significant factors by considering technical and economical aspects for material manufacturing. The contribution percentage $\left(\rho_{i}\right)$ can be calculated using Equation 2 as follows:

$$
\rho_{i}=\frac{S_{i}^{\prime}}{S_{T}} \times 100 \%
$$

where $S_{i}$ is the sum square of factors, $i$ is the number of factors and $S_{T}$ is the total sum of squares [73].

\subsection{Fabrication of bioepoxy/clay nanocomposites}

Bioepoxy blends were prepared by replacing commercial DGEBA epoxy with 0,20 , 60 and $80 \mathrm{wt} \%$ ESO in material formulation. Bioepoxy blends were prepared by using a magnetic stirrer at $200 \mathrm{rpm}$ and $25^{\circ} \mathrm{C}$ for $15 \mathrm{~min}$. Clay fillers at different weight fractions from 1 to $8 \mathrm{wt} \%$ were slowly added and mixed with the blends using a glass rod. The clay dispersion was then initiated via mechanical shear mixing using an IKARW20 mechanical mixer to break up large clay aggregates, which was followed by the ultrasonication with the aid of an ELMA Ti-H-5 ultrasonic bath with the power intensity of $90 \%$ at $50^{\circ} \mathrm{C}$ to disperse fine clay particle into bioepoxy matrices. The relevant material composition and material processing parameters are listed in Table 1, along with the setup of DoE trials illustrated in Table 2. Subsequently, the mixture was placed in a vacuum oven at $50^{\circ} \mathrm{C}$ to reduce air bubbles a few times until no bubble entrapment remained within the mixture. The mixture was then allowed to cool down to ambient temperature. Further, the curing agent was added to the mixture and stirred well with a glass rod for approximately $3 \mathrm{~min}$. This was followed by a degassing step using the ultrasonic bath for $5 \mathrm{~min}$. Subsequently, mixed slurries were syringe-injected into moulds cavities to complete pre-curing and post curing processes. Nanocomposite 
batches in DoE trials prepared using IPDA were cured at $25^{\circ} \mathrm{C}$ for $24 \mathrm{~h}$ and then subjected to post-curing at $100^{\circ} \mathrm{C}$ for $10 \mathrm{~h}$ and further $120^{\circ} \mathrm{C}$ for an hour. In comparison, due to different material characteristics and reactions, those batches cured with MTHPA were first cured at $80^{\circ} \mathrm{C}$ for $24 \mathrm{~h}$ prior to the post-curing process at $120^{\circ} \mathrm{C}$ for $3 \mathrm{~h}$.

\subsection{Characterisation}

\subsubsection{Tensile testing}

Tensile tests of bioepoxy/clay nanocomposites were conducted on type IV dog-bone specimens at $25^{\circ} \mathrm{C}$ according to ASTM D638. Specimens were tested on a Lloyds EZ50 universal testing machine with a crosshead speed of $5 \mathrm{~mm} / \mathrm{min}$. Data for tensile properties were collected with at least five measurements from each DoE trial to report average data and associated standard deviations.

\subsubsection{Morphological characterisation}

The tensile fracture surfaces of selected specimens were examined by a Zeiss Neon 40EsB scanning electron microscope (SEM) at an accelerating voltage of $5 \mathrm{kV}$. The fracture surface samples were pre-coated with platinum layers with the thickness of 5 $\mathrm{nm}$ in order to avoid charging effects.

Clay dispersion status within bioepoxy matrices was observed via a JEOL 2100 transmission electron microscope (TEM) at an accelerating voltage of $120 \mathrm{kV}$ with microscopic images recorded using a Gatan Orius CCD camera. Ultrathin TEM samples (average thickness: $\sim 100 \mathrm{~nm}$ ) were sectioned at room temperature using a Leica EM UC6 ultramicrotome mounted with glass knife before being collected on 300-mesh copper grids. 


\section{Results and discussion}

\subsection{Tensile strength of bioepoxy/clay nanocomposites}

Tensile strengths of neat bioepoxy and bioepoxy/clay nanocomposites based on different curing agents are depicted in Figure 1. Overall, it can be noted that bioepoxy/clay nanocomposites cured with IPDA have achieved higher tensile strengths when compared to those with MTHPA at the ESO contents of 0 and $20 \mathrm{wt} \%$. Nevertheless, an opposite trend in tensile strength was observed when the ESO content increased beyond $60 \mathrm{wt} \%$. According to Table 2, the highest tensile strength was achieved at $49.56 \mathrm{MPa}$ for bioepoxy/clay nanocomposites based on IPDA with the inclusion of $1 \mathrm{wt} \% \mathrm{CNa}^{+}$and $0 \mathrm{wt} \%$ ESO (i.e., BC1). The second best result was achieved at $41.37 \mathrm{MPa}$, namely bioepoxy/clay nanocomposites based on IPDA with 0 wt\% ESO and $3 \mathrm{wt} \% \mathrm{C10A}$ (i.e., BC8). However, their corresponding tensile strength (i.e., $\mathrm{BC} 1$ and $\mathrm{BC} 8$ ) were still found to be $17 \%$ and $30 \%$ lower, respectively, as opposed to that of neat conventional epoxy. Furthermore, other conventional nanocomposites, namely $\mathrm{BC} 3$, demonstrates a similar result, which was $28 \%$ lower than that of neat epoxy cured by MTHPA. Nevertheless, as for conventional nanocomposites reinforced with $5 \mathrm{wt} \% \mathrm{C} 15$ and cured by MTHPA (i.e., BC2), their tensile strengths were significantly improved by $69 \%$ relative to that of corresponding neat epoxy. Admittedly, such results are still below those of bioepoxy/clay nanocomposites cured by IPDA.

On the other hand, the addition of ESO was found to significantly alter the properties of resulting bioepoxy/clay nanocomposites relative to that of neat bioepoxy despite the fact that those values were still lower than those of conventional epoxy/clay nanocomposites. Tensile strengths of bioepoxy/clay nanocomposites (ESO content: 20 wt $\%$ ) cured by IPDA were improved by 37 and $15 \%$ with the addition of 3 wt $\%$ C15 (i.e., BC5) and $5 \mathrm{wt} \%$ C93 A (i.e., BC15), respectively when compared with that of 
neat bioepoxy. However, for those bioepoxy/clay nanocomposites cured by MTHPA, tensile strengths of $\mathrm{BC} 4$ with 8 wt $\% \mathrm{CNa}^{+}$and $\mathrm{BC} 11$ with 1 wt $\% \mathrm{C} 10 \mathrm{~A}$ were determined to be 3.58 and $20.82 \mathrm{MPa}$, respectively, which appeared to be lower than those of BC5 and BC15.

More noticeably, with increasing the ESO content beyond $60 \mathrm{wt} \%$, tensile strengths of bioepoxy/clay nanocomposites were decreased by almost $99 \%$ when cured by both IPDA and MTHPA as compared to that of conventional epoxy/clay nanocomposites. This highly declining trend of tensile strength can be attributed to the plasticised effect of ESO with the provision of more pronounced rubbery phases in bioepoxy blends with a lower crosslinking density as opposed to that of conventional epoxy $[39,49,74]$. Conversely, tensile strengths of bioepoxy/clay nanocomposites (ESO content: 60 wt $\%$ ), filled with $1 \mathrm{wt} \% \mathrm{C} 15$ (i.e., BC12) and $3 \mathrm{wt} \%$ C93A (i.e., BC16) while cured by MTHPA, were significantly enhanced by 203 and 29\%, respectively, when compared to that of neat bioepoxy. Moreover, these values were detected to be 410 and $198 \%$ higher than that of corresponding bioepoxy/8 wt\% C10A nanocomposites cured by IPDA (i.e., BC13). Similarly, the good compatibility between ESO and MTHPA was also presented as a result of an increase in tensile strength of bioepoxy/clay nanocomposites at the ESO content of $80 \%$. The tensile strengths of such bionanocomposites cured by MTHPA were increased by 398 and 38\% with additional 5 wt\% C10A (i.e., BC10) and 3 wt\% C93A (i.e., BC14), respectively, as opposed to that of neat bioepoxy. As such, the increase in tensile strength could be associated with the proper compatibility between bioepoxy blends and curing agents in terms of their reactivity to produce crosslinking bonds. The reactivity of curing agents can enhance the crosslinking density of molecular chains in bioepoxy blends, further inducing the improvement of tensile strengths $[4,15,72]$. 
In addition to the effect of ESO content, tensile strengths of bionanocomposites can also be influenced by the effect of clay content, depicted in Figure 1. In bioepoxy/clay nanocomposites with the ESO content of $20 \mathrm{wt} \%$, the inclusion of $3 \mathrm{wt} \%$ Cloisite 15 (i.e., BC5) was shown to significantly increase the tensile strength of nanocomposites cured by IPDA up to approximately $38.77 \mathrm{MPa}$, which is equivalent to $36.9 \%$ increase relative to that of neat bioepoxy at $28.23 \mathrm{MPa}$. On the contrary, bioepoxy/Cloisite $\mathrm{Na}^{+}$ nanocomposites cured by MTHPA demonstrated a strength reduction about $71 \%$ at the clay content of $8 \mathrm{wt} \%$ (i.e., BC4). Bioepoxy/clay nanocomposites reinforced with 1 wt $\%$ Cloisite 15 at the ESO content of $60 \mathrm{wt} \%$ (i.e., BC12) yielded the highest tensile strength when compared with those of other corresponding nanocomposite samples (i.e., BC6, BC13 and $\mathrm{BC} 16)$ and neat bioepoxy. In particular, the tensile strength of bioepoxy/clay nanocomposites cured by MTHPA at the ESO content of $80 \mathrm{wt} \%$ appeared to be higher than that of neat bioepoxy. In particular, bioepoxy at the ESO content $80 \mathrm{wt} \%$ cured by IPDA could be successfully fabricated in material processing. However, it could not be used to conduct tensile tests due to its high rubbery-like gel characteristic to cause the shape damage of prepared dog-bone tensile specimens after demoulding. Consequently, mechanical properties of such bioepoxy were not attainable for any data comparison. Overall, the inclusion of well-dispersed clay fillers into bioepoxy blends can improve tensile strengths of nanocomposites. Nonetheless, petroleum-based DGEBA epoxy resin revealed a reduction in tensile strengths of nanocomposites, which could be explained by the presence of clay platelet layers to hinder the crosslinking reaction between epoxy monomers [23].

\subsection{Morphological structures of bioepoxy/clay nanocomposites}

The surface morphologies of selected trial batches were illustrated in Figure 2, which indicated rough fracture surfaces of bioepoxy/clay nanocomposites due to the inclusion 
of clay fillers. Moreover, microcracks were also evident resulting from applied uniaxial loads during tensile tests. Moreover, SEM images clearly show visible clay layers representing better clay wettability and stronger interfacial bonding between clay fillers and matrices (i.e., BC2, BC5 and BC11 in Figures 2(c-h)), as opposed to BC1 samples in Figures $2 \mathrm{a}$ and $\mathrm{b}$. The fracture surface of $\mathrm{BC} 1$ in Figure $2 \mathrm{~b}$ exhibited the availability of crack propagation at the interphase layers between clay fillers and matrices due to applied loads. Such microcracks could be ascribed to the weak interfacial bonding owing to the reduced chemical reaction between clay layers and matrices.

Also of interest is that bioepoxy nanocomposites cured with IPDA (i.e., BC5) exhibited spherical domains of soybean droplets dispersed throughout matrices with the diameter at approximately $1 \mu \mathrm{m}$, as shown in Figures $2 \mathrm{e}$ and $\mathrm{f}$. The presence of oil droplets was indicative of phase separation, which might influence the reactivity of IPDA in that IPDA is generally more reactive with DGEBA rather than with ESO [24, 25, 75]. Meanwhile, typical bioepoxy/clay nanocomposite samples cured by MTHPA (BC11 samples) did not induce the phase separation in accordance with previous results obtained from Altuna et al. [27]. This finding implied that ESO/MTHPA had better compatibility and higher crosslinking density than ESO/IPDA, which was evidenced by tensile strength results of neat bioepoxy and bioepoxy/clay nanocomposites at the ESO content beyond 60\% (Figure 1 and Table 2).

TEM analysis was carried out to investigate clay dispersion state within bioepoxy matrices, as depicted in Figure 3. The dark lines and dots represented clay layers and particles while the bright regions presented bioepoxy matrices. As can be seen in Figures $3 \mathrm{a}$ and $\mathrm{b}$, poor clay dispersion occurred for nanocomposites reinforced with Cloisite $\mathrm{Na}^{+}$(i.e., BC1), along with microsized clay aggregates detected at approximately $2 \mu \mathrm{m}$ in local areas. Moreover, the combination of agglomerated, 
intercalated and partially exfoliated clay structures were observed at high magnification levels in TEM images, Figure 3b. On the other hand, clay platelet layers were moderately dispersed in epoxy matrices for BC2 as depicted in Figures $3 \mathrm{c}$ and $\mathrm{d}$. The TEM images also demonstrated the disorientation of intercalated structures instead of exfoliated counterparts. Detailed images including clay intercalated structures can be seen in Figure $3 \mathrm{~b}$ while single layers of localised clay platelets were detected as a sign of clay exfoliation.

On the other hand, the functionalisation of $20 \%$ ESO on bioepoxy/clay nanocomposites with 3 wt\% C15 (i.e., BC5 in Figures 3e and f) and 1wt\% C10A (BC11, Figures $3 \mathrm{~g}$ and $\mathrm{h}$ ) demonstrated a mix of intercalated and exfoliated clay structures. The single black lines and small black dots represented typical layers of well dispersed clay platelets throughout sectioned nanocomposite samples. Moreover, BC5 samples (Figure 3f) clearly illustrated clay intercalated structures with size variations in clay layer areas, indicating the multidirectional orientation of clay layers. Similarly, BC11 samples, as shown in Figures $3 \mathrm{~g}$ and $\mathrm{h}$ at higher magnifications, also presented similar orientations of clay layers in intercalated/exfoliated structures. Hence, it is clear that the functionalisation of bio-renewable ESO could enhance clay wettability in epoxy matrices, resulting in better interaction between matrices and fillers. However, as previously mentioned by Zhu and Wool [50] clay types (i.e., natural and organomodified clays) influenced the wettability of clay fillers in continuous matrices in nanocomposite systems. The incorporation of organomodified clay fillers was believed to improve clay wettability and interfacial bonding between clay fillers and epoxy matrices in contrast with those filled by natural clays. This was most likely associated with the presence of alkylammonium ion in clay interlayers for the effective improvement of clay wettability [48]. 


\subsection{Pareto ANOVA}

With the aid of Pareto ANOVA, significant factors and contribution percentages of factors in relation to manufacturing bioepoxy/clay nanocomposites to achieve the maximisation of tensile strength can be identified. Figure 4 depicted contribution percentages of all factors on manufacturing bioepoxy/clay nanocomposites. Significant factors were determined based on cumulative contribution percentages over $90 \%$ from the highest to the lowest levels. From these results, ESO content (factor A) was detected to be the most significant factor for tensile strength with a contribution percentage of $66.63 \%$ amongst nine factors in this study, Figure 4 . This significant factor was followed by mechanical mixing speed (factor E) and clay content (factor C) with contribution percentages of 19.09 and $7.01 \%$, respectively. On the other hand, other factors (i.e., clay type, curing agent type, sonication time, sonication frequency, mechanical mixing temperature and mechanical mixing time) yielded contribution percentages of $3.58,1.89,1.50,0.16,0.14$ and $0.01 \%$, respectively, which could thus be categorised as non-significant factors with their total contribution percentage being lower than $10 \%$.

\subsection{Preferred combination of factors of bioepoxy/clay nanocomposites}

As shown in Figure 5, optimal material formulation and processing parameters for "larger the better" characteristic used in the Taguchi DoEs for manufacturing bioepoxy/clay nanocomposites can be identified by selecting the largest average data of $S / N$ ratios for each controlled factor. The preferred combination of factors would therefore represent the optimal formulation in order to achieve highest tensile properties. For the tensile strength, as plotted in Figure 5, $\mathrm{A}_{1} \mathrm{~B}_{3} \mathrm{C}_{1} \mathrm{D}_{1} \mathrm{E}_{1} \mathrm{~F}_{2} \mathrm{G}_{1} \mathrm{H}_{2} \mathrm{I}_{1}$ was identified as the preferred combination of factors for the target response to the maximum tensile strength. Such optimal factors are 0\% ESO content, Cloisite 15 for 
clay type, $1 \mathrm{wt} \%$ for clay loading, IPDA for curing agent type, $200 \mathrm{rpm}$ for mechanical mixing speed, $85^{\circ} \mathrm{C}$ for mixing temperature with a mixing period of an hour, and 45 $\mathrm{kHz}$ for sonication frequency with a sonication period of an hour.

As observed in the plot for contribution percentages and ANOVA diagram, demonstrated in Figures 4 and 5 accordingly, mechanical mixing speed is the only significant factor in processing parameters to influence the tensile strength of bioepoxy/clay nanocomposites. However, others processing factors appeared to be insignificant though those factors were known to be fundamental in the clay dispersion process within polymer matrices. Furthermore, in a subsequent analysis for nonsignificant factors considering economical and technical aspects, the lowest factorial level could be employed accordingly (i.e., mechanical mixing at $25^{\circ} \mathrm{C}$ and $45 \mathrm{kHz}$ for an hour). This combination of factors would be sufficient to produce intercalated or even exfoliated clay structures by dispersing clay platelets into bioepoxy matrices.

\subsection{DoE confirmation}

To validate this preferred combination of factors, further experimental confirmation test based on the optimum condition and the preferred combination of factors was required, which was then compared with statistical confirmation tests. As mentioned previously, optimum tensile properties can be estimated by using the cumulative contribution percentage of $90 \%$ for significant factors and the optimum levels of each factor. Meanwhile, the economical and technical aspects were also taken into account when selecting non-significant factors and levels.

Based on ANOVA results, significant factors and levels for manufacturing bioepoxy/clay nanocomposites with optimum tensile strength were $0 \%$ for the ESO content (factor A, 66.63\%), 1wt\% for the clay content (factor C, 19.09\%) and $200 \mathrm{rpm}$ for mechanical mixing speed (factor E, 7.01\%). Non-significant factors, including clay 
and curing agent types, were selected from a technical viewpoint, which was deemed as the optimal value of sum of $S / N$ ratios. These included Cloisite 15 for clay type (level 3) and the use of IPDA curing agent (level 1), respectively. Moreover, other nonsignificant factors (i.e., mechanical mixing temperature and time, and sonication frequency and time) were chosen according to economical and technical consideration. In non-significant factors, the combination of factors comprised $25^{\circ} \mathrm{C}$ for $1 \mathrm{~h}$ in the mechanical mixing process and $45 \mathrm{kHz}$ for $1 \mathrm{~h}$ in the subsequent sonication process. When predicted results were determined for the optimum condition, only significant factors were considered. In this case, ESO content $\left(\mathrm{A}_{1}\right)$, clay content $\left(\mathrm{C}_{1}\right)$ and mechanical mixing speed $\left(E_{1}\right)$ were selected. The comparison between confirmation test results and predicted data were listed in Table 3 . The predicted values ( $\mu_{\text {prediction }}$ ) of a preferred combination of factors could be calculated using Equation 3 below:

$$
\mu_{\text {prediction }}=T+\left(A_{1}-T\right)+\left(C_{1}-T\right)+\left(E_{1}-T\right)
$$

where $T$ is the average of the sum of $S / N$ ratio. $A_{l}, C_{l}$ and $E_{1}$ are the sum of $S / N$ ratio for each significant factorial level [76].

In Table 3, it was evidently seen that two confirmation test results in relation to tensile strengths of bioepoxy/clay nanocomposites were slightly lower with the sum of $S / N$ ratio being approximately 1.22 and $2.86 \mathrm{~dB}$ with the ESO contents of 0 and 20 wt $\%$, respectively. Furthermore, to confirm the validity of a preferred combination of factors, the calculation of confidence interval (C.I) is generally used as mentioned elsewhere [73,76]. For engineering experiments, the reasonable agreement between predicted values and confirmation results should be within $\pm 5 \%$ (i.e., the confidence interval of over 95\%). Equations 4 and 5 presented mathematical calculations of confidence intervals for predicted and confirmation results, respectively, as follows: 


$$
\begin{gathered}
C . I_{\text {Predicted }}=\sqrt{F_{\alpha, v_{1}, v_{2}} \times V_{e} \times\left[\frac{1}{n_{e f f}}\right]} \\
\text { C. } \text { I }_{\text {Confirmation }}=\sqrt{F_{\alpha, v_{1}, v_{2}} \times V_{e} \times\left[\frac{1}{n_{e f f}}+\frac{1}{r}\right]}
\end{gathered}
$$

where $F_{a, v l, v_{2}}$ is the $F$-ratio value from the $F$ table. $\alpha$ is risk in which the confidence level is ( $1-$ risk). $v_{1}$ is the degree of freedom for the numerator with a mean, which is generally equal to 1 . Moreover, $v_{2}$ is the degree of freedom for the denominator associated with the degrees of freedom for the pooled error variance. $V_{\mathrm{e}}, \mathrm{n}_{\text {eff }}$ and $r$ are pooled error variance, number of effective replication and number of replicas, respectively.

The calculation results of confidence intervals for predicted and confirmation results can be seen in Figure 6. A large degree of overlap was observed between the C.I confirmation and predicted results, indicating that predicted values were well acceptable to be used in the optimum processing of bioepoxy/clay nanocomposites. Nonetheless, good reproducibility could be achieved through the numerical addition of significant factors predicted from Pareto ANOVA [76].

\section{Conclusions}

The preferred combination of factors for manufacturing bioepoxy/clay nanocomposites, including material formulation and processing parameters, have been studied using Taguchi DoEs with a mixed factorial level. Tensile strength results were used as a typical DoE response to achieve optimal material properties via Pareto ANOVA. SEM and TEM analyses were employed to determine morphological structures and wettability of bioepoxy/clay nanocomposites. Based on Pareto ANOVA, 
ESO content was determined to be the most significant factor in maximising tensile strengths of nanocomposites amongst all nine factors. The increase of ESO content gave rise to the significant reduction in tensile strength values of nanocomposites due to ESO plasticisation effect. Furthermore, mechanical mixing speed was shown to be the second most significant factor, which was followed by clay content. The lower mixing speed of $200 \mathrm{rpm}$ was sufficient to break up clay aggregates and disperse clay particles within polymer matrices. The clay content of $1 \mathrm{wt} \%$ was determined to enhance tensile strengths of nanocomposites at an optimum level. Other factors, such as clay type, curing agent type, mechanical mixing temperature and time, as well as sonication frequency and time could be categorised as non-significant factors, considering that their cumulative contribution percentage was lower than $10 \%$. Notwithstanding that results based on the preferred combination of factors were slightly lower than predicted values, satisfactory confidence interval at $95 \%$ was successfully achieved for the validity of using DoE approach.

\section{Acknowledgement}

H. Salam gratefully acknowledges the Directorate General of Resources for Science, Technology and Higher Education, Ministry of Research, Technology and Higher Education of Indonesia, Government of Republic Indonesia, to grant him a $\mathrm{PhD}$ scholarship (Reference No. 4866/ E4.4/K/635 2013).

\section{References}

1. Mülhaupt, R. Green polymer chemistry and bio-based plastics: Dreams and reality. Macromol. Chem. Phys. 2013;214:159-174.

2. Supanchaiyamat, N, Hunt, AJ, Shuttleworth, PS, Ding, C, Clark, JH, Matharu, AS. Bio-based thermoset composites from epoxidised linseed oil and expanded starch. RSC Adv. 2014;4:23304-23313. 
3. Czub, P. Application of modified naturaloils as reactive diluents for epoxy resins. Macromol. Symp. 2006;242:60-64.

4. Gupta, AP, Ahmad, S, Dev, A. Development of novel bio-based soybean oil epoxy resins as a function of hardener stoichiometry. Polym. Plast. Technol. Eng. 2010;49:657-661.

5. Khot, SN, Lascala, JJ, Can, E, Morye, SS, Williams, GI, Palmese, GR, Kusefoglu, SH, Wool, RP. Development and application of triglyceride-based polymers and composites. J. Appl. Polym. Sci. 2001;82:703-723.

6. Manthey, NW, Cardona, F, Aravinthan, T. Cure kinetic study of epoxidized hemp oil cured with a multiple catalytic system. J. Appl. Polym. Sci. 2012;125:E511-E517.

7. Mauck, SC, Wang, S, Ding, W, Rohde, BJ, Fortune, CK, Yang, G, Ahn, S-K, Robertson, ML. Biorenewable tough blends of polylactide and acrylated epoxidized soybean oil compatibilized by a polylactide star polymer. Macromolecules. 2016;49:1605-1615.

8. Miyagawa, H, Misra, M, Drzal, LT, Mohanty, AK. Novel biobased nanocomposites from functionalized vegetable oil and organically-modified layered silicate clay. Polymer. 2005;46:445-453.

9. Park, S-J, Jin, F-L, Lee, J-R. Effect of biodegradable epoxidized castor oil on physicochemical and mechanical properties of epoxy resins. Macromol. Chem. Phys. 2004;205:2048-2054.

10. Ratna, D, Banthia, AK. Epoxidized soybean oil toughened epoxy adhesive. J. Adhes. Sci. Technol. 2000;14:15-25.

11. Tan, SG, Ahmad, Z, Chow, WS. Interpenetrating polymer network structured thermosets prepared from epoxidized soybean oil/diglycidyl ether of bisphenol A. Polym. Int. 2014;62:273-279.

12. Zhang, J, Hu, S, Zhan, G, Tang, X, Yu, Y. Biobased nanocomposites from clay modified blend of epoxidized soybean oil and cyanate ester resin. Prog. Org. Coat. 2013;76:1683-1690.

13. Niedermann, P, Szebényi, G, Toldy, A. Effect of epoxidized soybean oil on curing, rheological, mechanical and thermal properties of aromatic and aliphatic epoxy resins. J. Polym. Environ. 2014;22:525-536.

14. Tan, SG, Chow, WS. Biobased epoxidized vegetable oils and its greener epoxy blends: A review. Polym. Plast. Technol. Eng. 2010;49:1581-1590. 
15. Shabeer, A, Sundararaman, S, Chandrashekhara, K, Dharani, LR. Physicochemical properties and fracture behavior of soy-based resin. J. Appl. Polym. Sci. 2007;105:656-663.

16. Raquez, JM, Deléglise, M, Lacrampe, MF, Krawczak, P. Thermosetting (bio)materials derived from renewable resources: A critical review. Prog. Polym. Sci. 2010;35:487-509.

17. Auvergne, R, Caillol, S, David, G, Boutevin, B, Pascault, J-P. Biobased thermosetting epoxy: Present and future. Chem. Rev. 2013;114:1082-1115.

18. Salam, H, Dong, Y, Davies, IJ. Development of bio-based polymer/clay nanocomposites: A critical review. In: Y. Dong, R. Umer, and A.K.-T. Lau, editors. Fillers and reinforcements for advanced nanocomposites. UK: Woodhead Publishing (In Imprint of Elsevier); 2015. p. 101-132.

19. Mohanty, AK, Misra, M, Hinrichsen, G. Biofibres, biodegradable polymers and biocomposites: An overview. Macromol. Mater. Eng. 2000;276-277:1-24.

20. Kim, JR, Sharma, S. The development and comparison of bio-thermoset plastics from epoxidized plant oils. Ind. Crops. Prod. 2012;36:485-499.

21. Ratna, D. Modification of epoxy resins for improvement of adhesion: A critical review. J. Adhes. Sci. Technol. 2003;17:1655-1668.

22. Ronda, JC, Lligadas, G, Galià, M, Cádiz, V. A renewable approach to thermosetting resins. React. Funct. Polym. 2013;73:381-395.

23. Shibata, M. Bio-based epoxy resin/clay nanocomposites, in Thermoset nanocomposites, M Vikas (Eds). Wiley-VCH Verlag GmbH \& Co. KGaA: Weinheim, Germany. 2013. p. 189-209.

24. Frischinger, I, Dirlikov, S. Toughening of epoxy resins by epoxidized soybean oil. In: R Keith and JK Anthony, editors. Toughened plastics I. USA: American Chemical Society; 1993. p. 451-489.

25. Sahoo, SK, Mohanty, S, Nayak, SK. Toughened bio-based epoxy blend network modified with transesterified epoxidized soybean oil: Synthesis and characterization. RSC Adv. 2015;5:13674-13691.

26. Park, S-J, Jin, F-L, Lee, J-R. Thermal and mechanical properties of tetrafunctional epoxy resin toughened with epoxidized soybean oil. Mater. Sci. Eng., A. 2004;374:109-114. 
27. Roudsari, GM, Mohanty, AK, Misra, M. Study of the curing kinetics of epoxy resins with biobased hardener and epoxidized soybean oil. ACS Sustain. Chem. Eng. 2014;2:2111-2116.

28. Karger-Kocsis, J, Grishchuk, S, Sorochynska, L, Rong, MZ. Curing, gelling, thermomechanical and thermal decomposition behaviors of anhydride-cured epoxy (DGEBA)/epoxidized soybean oil compositions. Polym. Eng. Sci. 2014;54:747-755.

29. Gogoi, P, Boruah, M, Sharma, S, Dolui, SK. Blends of epoxidized alkyd resins based on jatropha oil and the epoxidized oil cured with aqueous citric acid solution: A green technology approach. ACS Sustain. Chem. Eng. 2015; 3:261268.

30. Altuna, FI, Espósito, L, Ruseckaite, RA, Stefani, PM. Syntactic foams from copolymers based on epoxidized soybean oil. Composites Part A. 2010;41:1238-1244.

31. Altuna, FI, Pettarin, V, Williams, RJJ. Self-healable polymer networks based on the cross-linking of epoxidised soybean oil by an aqueous citric acid solution. Green Chem. 2013;15:3360-3366.

32. Gupta, AP, Ahmad, S, Dev, A. Modification of novel bio-based besinepoxidized soybean oil by conventional epoxy resin. Polym. Eng. Sci. 2011;51:1087-1091.

33. Jin, F-L, Park, S-J. Thermomechanical behavior of epoxy resins modified with epoxidized vegetable oils. Polym. Int. 2008;57:577-583.

34. Liu, Z, Erhan, SZ. "Green" composites and nanocomposites from soybean oil. Mater. Sci. Eng., A. 2008;483-484:708-711.

35. Sorrentino, A, Gorrasi, G, Vittoria, V. Potential perspectives of bionanocomposites for food packaging applications. Trends Food Sci. Technol. 2007; 18: 84-95.

36. Miyagawa, H, Misra, M, Drzal, LT, Mohanty, AK. Fracture toughness and impact strength of anhydride-cured biobased epoxy. Polym. Eng. Sci. 2005;45:487-495.

37. Park, S-J, Jin, F-L, Lee, J-R. Synthesis and thermal properties of epoxidized vegetable oil. Macromol. Rapid Commun. 2004;25:724-727.

38. Ratna, D. Mechanical properties and morphology of epoxidized soyabean-oilmodified epoxy resin. Polym. Int. 2001;50:179-184. 
39. Altuna, FI, Espósito, LH, Ruseckaite, RA, Stefani, PM. Thermal and mechanical properties of anhydride-cured epoxy resins with different contents of biobased epoxidized soybean oil. J. Appl. Polym. Sci. 2011;120:789-798.

40. Tanrattanakul, V, Saithai, P. Mechanical properties of bioplastics and bioplastic-organoclay nanocomposites prepared from epoxidized soybean oil with different epoxide contents. J. Appl. Polym. Sci. 2009;114:3057-3067.

41. Bhuyan, S, Sundararajan, S, Lu, Y, Larock, RC. A study of the physical and terminological properties of biobased polymer-clay nanocomposites at different clay concentrations. Wear. 2010;268:797-802.

42. Sermsantiwanit, K, Phattanarudee, S. Preparation of bio-based nanocomposite emulsions: Effect of clay type. Prog. Org. Coat. 2012;74:660-666.

43. Albayrak, Ö, Şen, S, Çayl, G, Ortaç, B. Bio-based polymer nanocomposites based on layered silicates having a reactive and renewable intercalant. J. Appl. Polym. Sci. 2013;130:2031-2041.

44. Reddy, MM, Vivekanandhan, S, Misra, M, Bhatia, SK, Mohanty, AK. Biobased plastics and bionanocomposites: Current status and future opportunities. Prog. Polym. Sci. 2013;38:1653-1689.

45. Wang, R, Schuman, T, Vuppalapati, RR, Chandrashekhara, K. Fabrication of bio-based epoxy-clay nanocomposites. Green Chem. 2014;16:1871-1882.

46. Takada, Y, Shinbo, K, Someya, Y, Shibata, M. Preparation and properties of bio-based epoxy montomorillonite nanocomposites derived from polyglycerol polyglycidyl ether and $\varepsilon$-polylysine. J. Appl. Polym. Sci. 2009;113:479-484.

47. Ishikawa, T. Overview of trends in advanced composite research and applications in Japan. Adv. Compos. Mater. 2006;15:3-37.

48. Lu, J, Hong, CK, Wool, RP. Bio-based nanocomposites from functionalized plant oils and layered silicate. J. Polym. Sci., Part B: Polym. Phys. 2004;42:1441-1450.

49. Miyagawa, H, Mohanty, A, Drzal, LT, Misra, M. Effect of clay and aluminananowhisker reinforcements on the mechanical properties of nanocomposites from biobased apoxy: A comparative study. Ind. Eng. Chem. Res. 2004;43:7001-7009.

50. Zhu, L, Wool, RP. Nanoclay reinforced bio-based elastomers: Synthesis and characterization. Polymer. 2006;47:8106-8115. 
51. Alexandre, M, Dubois, P. Polymer-layered silicate nanocomposites: Preparation, properties and uses of a new class of materials. Mater. Sci. Eng. R Rep. 2000;28:1-63.

52. Shi, Y, Kanny, K, Jawahar, P. Hybrid nanocomposites: Processing and properties. Adv. Compos. Mater. 2009;18:365-379.

53. T.P, M, Kanny, K. Effect of nanoclay in HDPE-glass fiber composites on processing, structure and properties. Adv. Compos. Mater. 2012;21:315-331.

54. Xie, F, Pollet, E, Halley, PJ, Avérous, L. Starch-based nano-biocomposites. Prog. Polym. Sci. 2013;38:1590-1628.

55. Dong, Y, Chaudhary, D, Ploumis, C, Lau, K-T. Correlation of mechanical performance and morphological structures of epoxy micro/nanoparticulate composites. Composites Part A. 2011;42:1483-1492.

56. Salam, H, Dong, Y, Davies, IJ, Pramanik, A. The effects of material formulation and manufacturing process on mechanical and thermal properties of epoxy/clay nanocomposites. Int. J Adv. Manf. Tech. 2016:1-14.

57. Chivrac, F, Pollet, E, Dole, P, Avérous, L. Starch-based nano-biocomposites: Plasticizer impact on the montmorillonite exfoliation process. Carbohydr. Polym. 2010;79:941-947.

58. Alateyah, A, I, Dhakal, H, N, Zhang, Z, Y. Processing, properties and applications of polymer nanocomposites based on layer silicates: A review. Adv. Polym. Tech. 2013;32:21368.

59. Bensadoun, F, Kchit, N, Billotte, C, Bickerton, S, Trochu, F, Ruiz, E. A study of nanoclay reinforcement of biocomposites made by liquid composite molding. Int. J. Polym. Sci. 2011;2011:10.

60. Das, G, Karak, N. Vegetable oil-based flame retardant epoxy/clay nanocomposites. Polym. Degrad. Stab. 2009;94: 1948-1954.

61. Atiemo-Obeng, VA, Penney, W, Armenante, PM. Solid-liquid mixing. In: EL Paul, VA Atiemo-Obeng and SM Kresta, editors. Handbook of industrial mixing: Science and practice. Hoboken: John Wiley \& Sons, Inc.; 2004. p. 543584.

62. Gupta, N, Lin, TC, Shapiro, M. Clay-epoxy nanocomposites: Processing and properties. JOM, 2007;59: 61-65. 
63. Park, JY, Davis, TB, Sullivan, PL. Parametric study on the fabrication of claycontaining thermosetting nanocomposites. J. Reinf. Plast. Compos. 2010;29:755-770.

64. Kaboorani, A, Riedl, B, Blanchet, P. Ultrasonication technique: A method for dispersing nanoclay in wood adhesives. J. Nanomater. 2013;2013:9.

65. Cravotto, G, Cintas, P. Introduction to sonochemistry: A historical and conceptual overview. In: Chen D, Sharma SK, and M. A, editors. Handbook on applications of ultrasound: Sonochemistry for sustainability. Boca Raton: CRC/Taylor \& Francis; 2011. p. 23-40.

66. Dean, K, Krstina, J, Tian, W, Varley, RJ. Effect of ultrasonic dispersion methods on thermal and mechanical properties of organoclay epoxy nanocomposites. Macromol. Mater. Eng. 2007;292:415-427.

67. Lam, C-K, Lau, K-T, Cheung, H-Y, Ling, H-Y. Effect of ultrasound sonication in nanoclay clusters of nanoclay/epoxy composites. Mater. Lett. 2005;59:13691372.

68. Park, SH. Robust design and analysis for quality engineering. London, UK: Chapman \& Hall; 1996.

69 Mustata, F, Tudorachi, N, Rosu, D. Curing and thermal behavior of resin matrix for composites based on epoxidized soybean oil/diglycidyl ether of bisphenol A. Compos. Part B: Engineering. 2011; 42:1803-1812.

70. Lu, Y, Larock, RC. Bio-based nanocomposites from corn oil and functionalized organoclay prepared by cationic polymerization. Macromol. Mater. Eng., 2007;292:863-872.

71. Miyagawa, H, Rich, MJ, Drzal, LT. Amine-cured epoxy/clay nanocomposites.

I. Processing and chemical characterization. J. Polym. Sci., Part B: Polym. Phys. 2004;42:4384-4390.

72. Liu, Z, Erhan, SZ, Xu, J. Preparation, characterization and mechanical properties of epoxidized soybean oil/clay nanocomposites. Polymer 2005; 46:10119-10127.

73. Roy, RK. A primer on the taguchi method. New York: Van Nostrand Reinhold; 1990.

74. Patel, MB, Patel, RG, Patel, VS. Effects of reactive diluent diepoxidized cardanol and epoxy fortifier on curing kinetics of epoxy resin. J. Therm. Anal. $1989 ; 35: 47-57$. 
75. Parzuchowski, PG, Jurczyk-Kowalska, M, Ryszkowska, J, Rokicki, G. Epoxy resin modified with soybean oil containing cyclic carbonate groups. J. Appl. Polym. Sci. 2006;102:2904-2914.

76. Belavendram, N. Quality by design. Taguchi techniques for industrial experimentation. London: Prentice Hall International; 1995. 


\section{List of Figures}

Figure 1. The effect of material formulation and processing parameters on tensile strengths of bioepoxy/clay nanocomposites. The symbols of NE_IPDA, NE_20ESO_IPDA, NE_60ESO_IPDA and NE_80ESO_IPDA represent neat epoxy, neat bioepoxy with $20 \mathrm{wt} \%$ ESO, $60 \mathrm{wt} \%$ ESO and $80 \mathrm{wt} \%$ ESO cured by IPDA, respectively. The symbols of NE_MTHPA, NE_20ESO_MTHPA, NE_60ESO_ MTHPA and NE_80ESO_MTHPA represent neat epoxy, neat bioepoxy with $20 \mathrm{wt} \%$ ESO, $60 \mathrm{wt} \%$ ESO and $80 \mathrm{wt} \%$ ESO cured by MTHPA, respectively. NE_MTHPA stands for neat conventional epoxy cured by MTHPA.

Figure 2. SEM micrographs of typical bioepoxy/clay nanocomposite samples at different magnifications: (a) BC1 at $1000 \times$, (b) BC1 at $10000 \times$, (c) BC2 at $1000 \times$, (d) BC2 at 10000×. (e) BC5 at 1000×, (f) BC5 at 10000×, (g) BC11 at 1000×, (h) BC11 at 10000x. The letters CA, MC, and OD represent clay aggregates, microcracks and oil droplets, respectively.

Figure 3. TEM images of typical bioepoxy/clay nanocomposite samples at different magnifications (a) BC1 at 500×, (b) BC1 at $30000 \times$ (c) BC2 at 500×, (d) BC2 at 30000×. (e) BC5 at 8000×, (f) BC5 at 30000×, (g) BC11 500×, (h) BC11 at 30000×. The letters CA, I and E represent clay aggregates, intercalated and exfoliated structures, respectively.

Figure 4. ANOVA diagrams of significant factors to maximise tensile strengths of bioepoxy/clay nanocomposites.

Figure 5. Average of $S / N$ ratio of each factor at different levels to maximise tensile strengths of bioepoxy/clay nanocomposites.

Figure 6. Comparison of confidence interval for predicted values and confirmation results of preferred combination factors to maximise tensile strengths of bioepoxy/clay nanocomposites with (a) $0 \mathrm{wt} \% \mathrm{ESO}$, (b) $20 \mathrm{wt} \%$ ESO. 


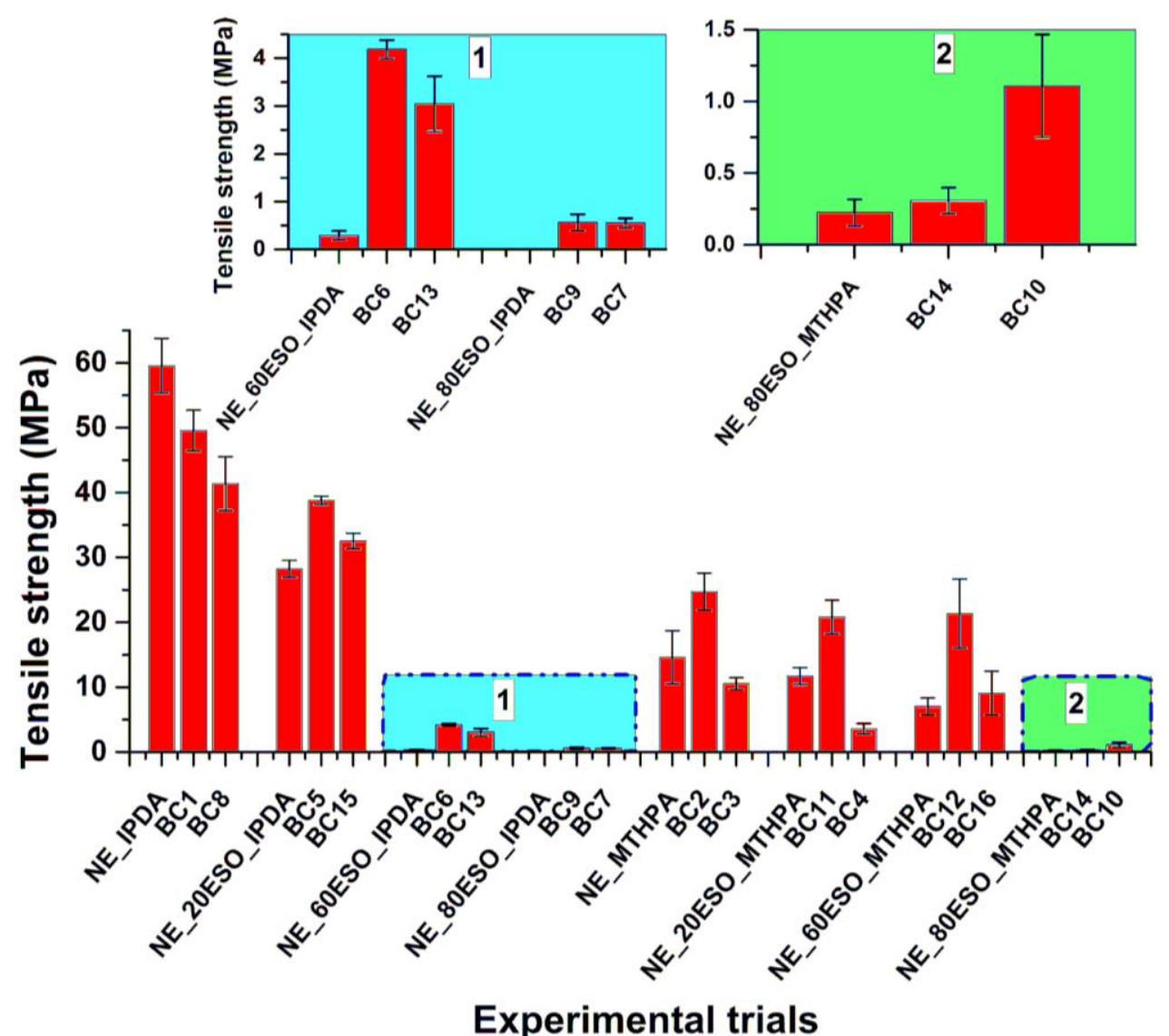

Figure 1 The effect of material formulation and processing parameters on tensile strengths of bioepoxy/clay nanocomposites. The symbols of NE_IPDA, NE_20ESO_IPDA, NE_60ESO_IPDA and NE_80ESO_IPDA represent neat epoxy, neat bioepoxy with 20 wt\% ESO, 60 wt\% ESO and 80 wt\% ESO cured by IPDA, respectively. The symbols of NE_MTHPA, NE_20ESO_MTHPA, NE_60ESO_ MTHPA and NE_80ESO_MTHPA represent neat epoxy, neat bioepoxy with $20 \mathrm{wt} \%$ ESO, $60 \mathrm{wt} \%$ ESO and $80 \mathrm{wt} \%$ ESO cured by MTHPA, respectively. NE_MTHPA stands for neat conventional epoxy cured by MTHPA. 


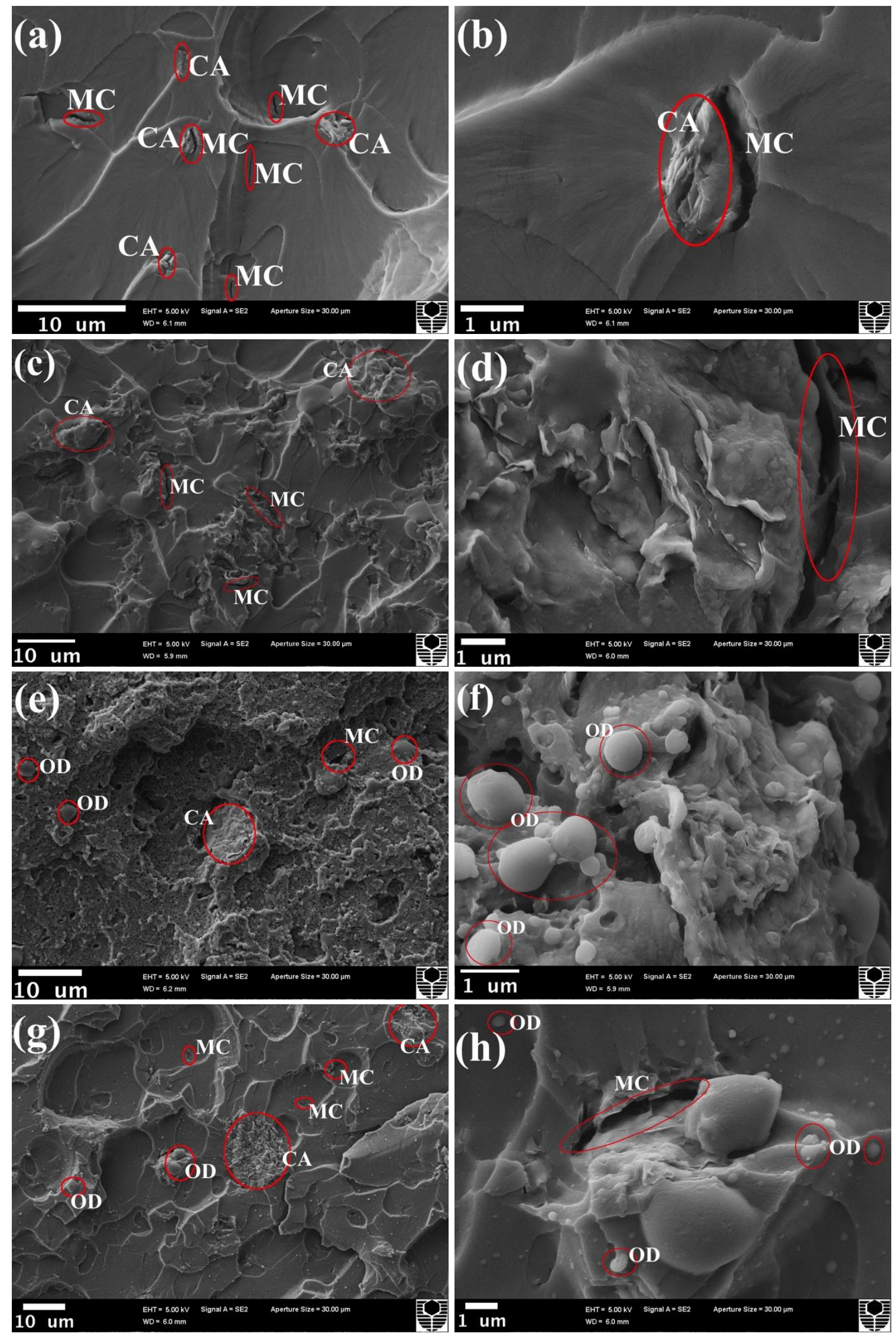

Figure 2 SEM micrographs of typical bioepoxy/clay nanocomposite samples at different magnifications: (a) BC1 at 1000×, (b) BC1 at 10000×, (c) BC2 at 1000×, (d) $\mathrm{BC} 2$ at $10000 \times$. (e) BC5 at $1000 \times$, (f) BC5 at $10000 \times$, (g) BC11 at $1000 \times$, (h) BC11 at $10000 \times$. The letters $\mathrm{CA}, \mathrm{MC}$, and $\mathrm{OD}$ represent clay aggregates, microcracks and oil droplets, respectively. 

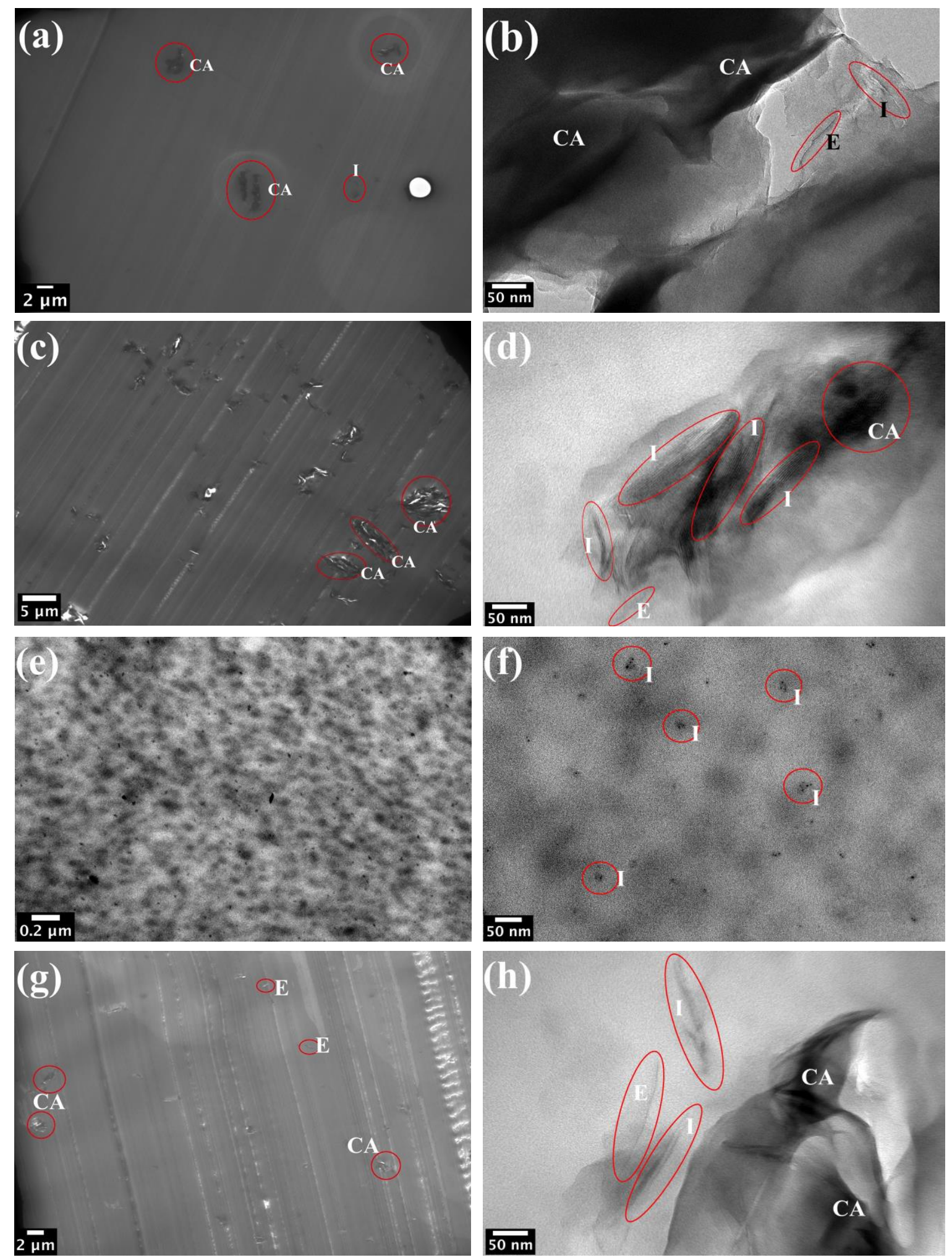

Figure 3 TEM images of typical bioepoxy/clay nanocomposite samples at different

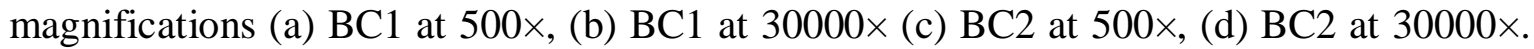
(e) BC5 at $8000 \times$, (f) BC5 at 30000×, (g) BC11 500×, (h) BC11 at 30000×. The letters $\mathrm{CA}$, I and $\mathrm{E}$ represent clay aggregates, intercalated and exfoliated structures, respectively. 


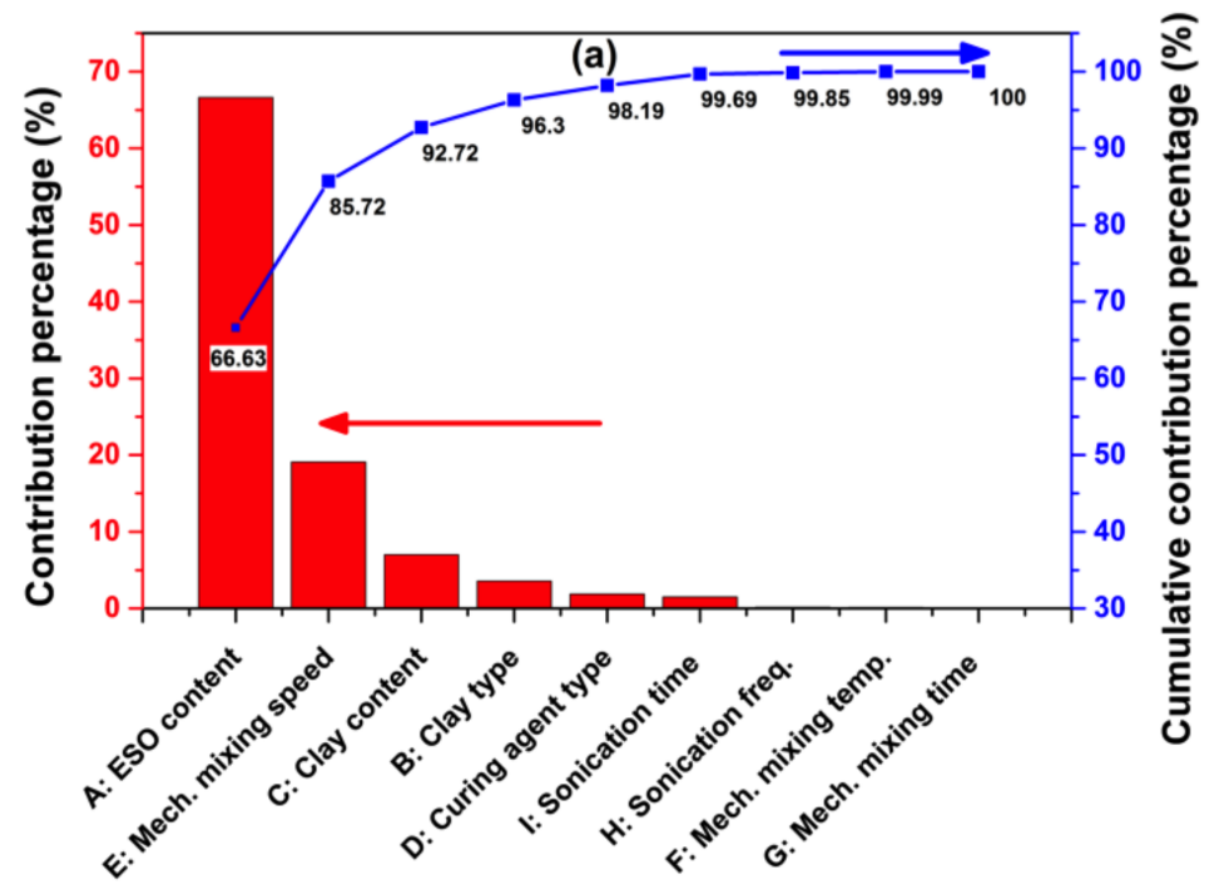

Factors

Figure 4 ANOVA diagrams of significant factors to maximise tensile strengths of bioepoxy/clay nanocomposites. 


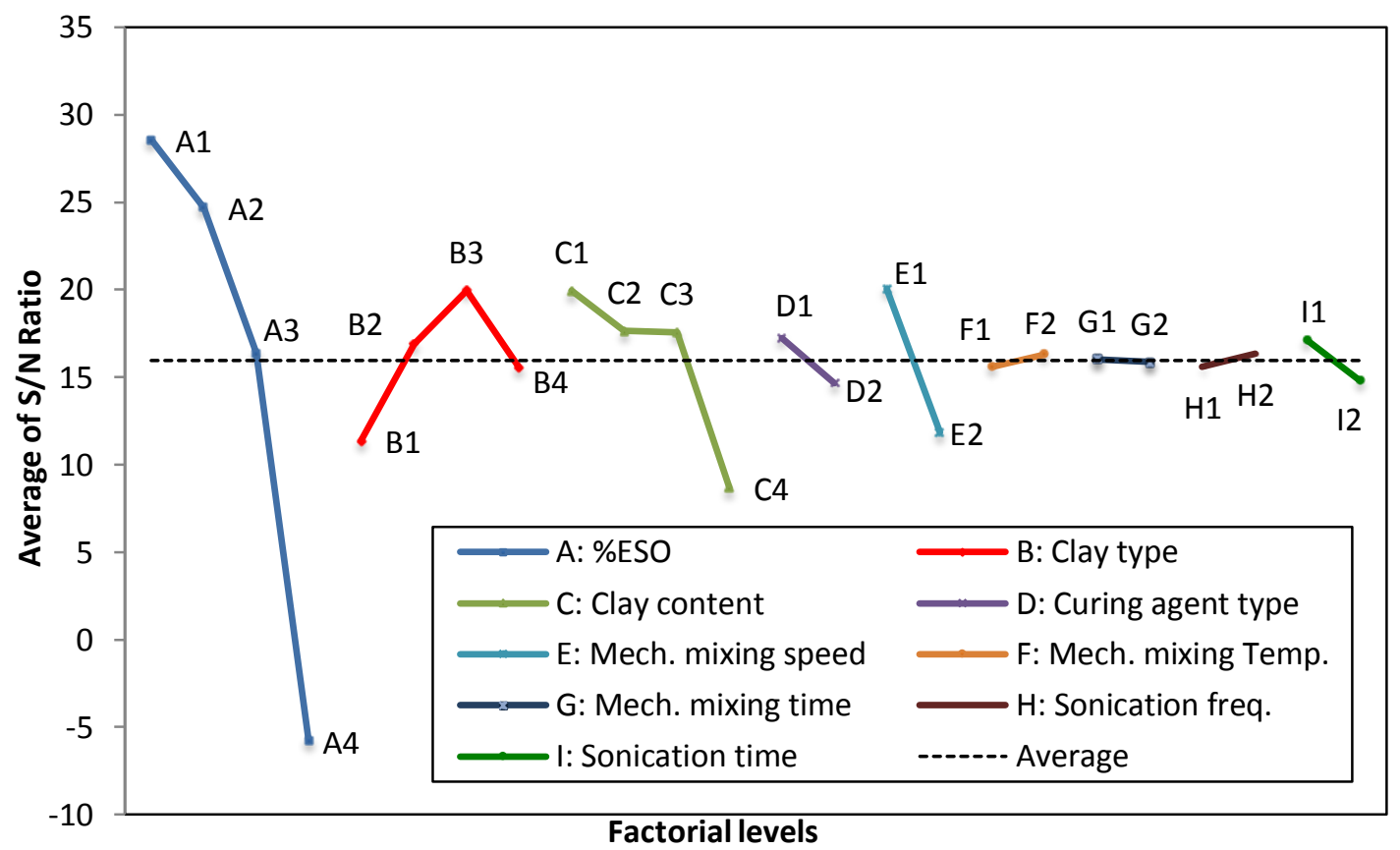

Figure 5. Average of $S / N$ ratio of each factor at different levels to maximise tensile strengths of bioepoxy/clay nanocomposites. 

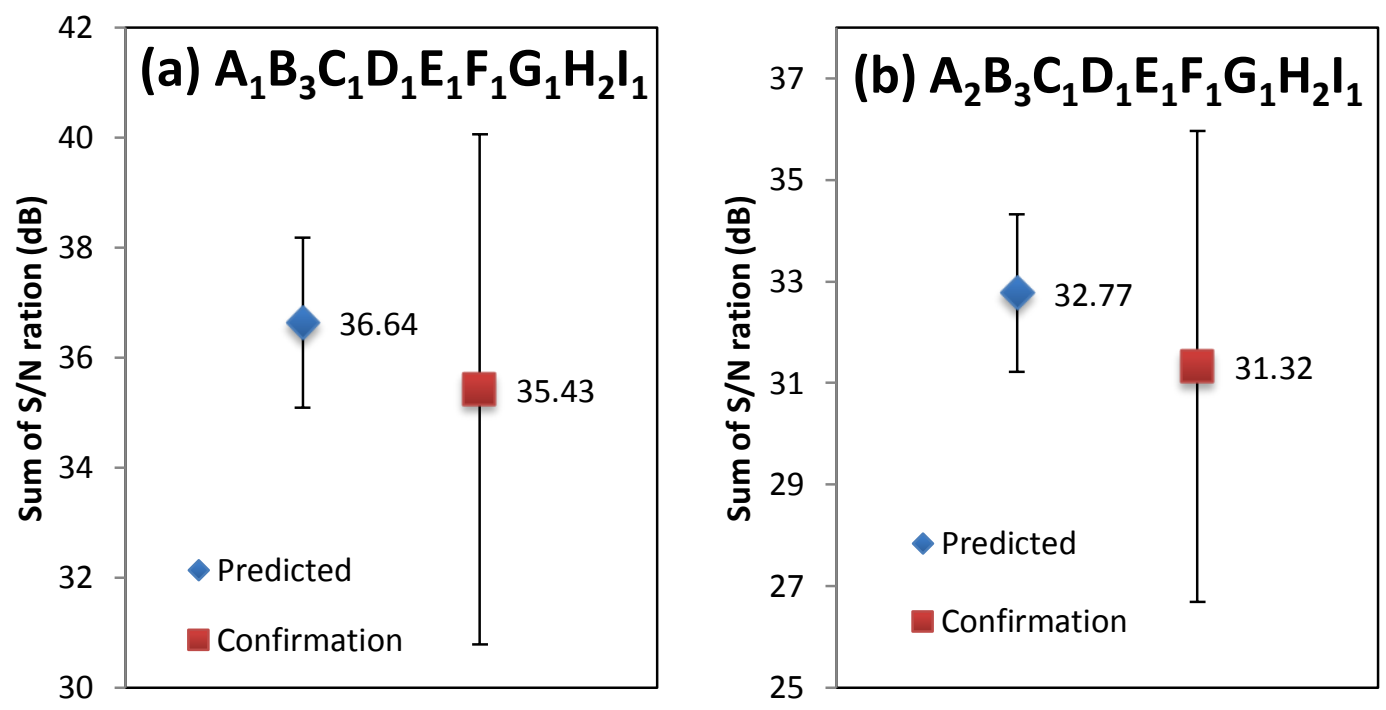

Figure 6. Comparison of confidence interval for predicted values and confirmation results of preferred combination factors to maximise tensile strengths of bioepoxy/clay nanocomposites with (a) 0 wt $\%$ ESO, (b) 20 wt $\%$ ESO. 
Table 1 Factors and levels used in mixed $\mathrm{L}_{16}$ DoE

\begin{tabular}{|c|c|c|c|c|}
\hline \multirow[t]{2}{*}{ Factors } & \multicolumn{4}{|c|}{ Levels } \\
\hline & 1 & 2 & 3 & 4 \\
\hline A: ESO content (wt\%) & 0 & 20 & 60 & 80 \\
\hline B: Clay type & $\mathrm{CNa}^{+}$ & $\mathrm{C} 10 \mathrm{~A}$ & $\mathrm{C} 15$ & C93A \\
\hline C: Clay content (wt\%) & 1 & 3 & 5 & 8 \\
\hline D: Curing agent type & IPDA & MTHPA & & \\
\hline E: Mechanical mixing speed (rpm) & 200 & 500 & & \\
\hline F: Mechanical mixing temperature $\left({ }^{\circ} \mathrm{C}\right)$ & 25 & 80 & & \\
\hline G: Mechanical mixing time (h) & 1 & 2 & & \\
\hline H: Sonication frequency $(\mathrm{kHz})$ & 25 & 45 & & \\
\hline I: Sonication time $(\mathrm{h})$ & 1 & 3 & & \\
\hline
\end{tabular}


Table 2. $\mathrm{L}_{16}$ DoE layout

\begin{tabular}{|c|c|c|c|c|c|c|c|c|c|c|c|c|}
\hline $\begin{array}{c}\text { Trial } \\
\text { number }\end{array}$ & $\%$ ESO & $\begin{array}{l}\text { Clay } \\
\text { type }\end{array}$ & $\begin{array}{l}\text { wt\% } \\
\text { Clay }\end{array}$ & $\begin{array}{l}\text { Curing } \\
\text { agent } \\
\text { type }\end{array}$ & $\begin{array}{c}\text { Mech. } \\
\text { mixing speed } \\
(\text { rpm })\end{array}$ & $\begin{array}{c}\text { Mech. } \\
\text { mixing } \\
\text { temp. }\left({ }^{\circ} \mathrm{C}\right)\end{array}$ & $\begin{array}{c}\text { Mech. } \\
\text { mixing time } \\
\text { (hours) }\end{array}$ & $\begin{array}{l}\text { Sonication } \\
\text { freq. }(\mathrm{kHz})\end{array}$ & $\begin{array}{c}\text { Sonication } \\
\text { time } \\
\text { (hours) }\end{array}$ & $\begin{array}{r}\text { Tensil } \\
\text { ( }\end{array}$ & $\begin{array}{l}\text { trength } \\
\text { a) }\end{array}$ & $\begin{array}{c}\text { S/N ratio } \\
\text { (dB) }\end{array}$ \\
\hline & A & B & C & D & $E$ & $F$ & G & $\mathrm{H}$ & $I$ & AVG & STDEV & \\
\hline BC1 & 0 & $\mathrm{CNa}^{+}$ & 1 & IPDA & 200 & 25 & 1 & 25 & 1 & 49.56 & 3.13 & 33.86 \\
\hline BC2 & 0 & C15 & 5 & MTHPA & 500 & 25 & 1 & 45 & 3 & 24.72 & 2.86 & 27.72 \\
\hline BC3 & 0 & C93A & 8 & MTHPA & 500 & 80 & 2 & 25 & 1 & 10.56 & 0.93 & 20.40 \\
\hline BC4 & 20 & $\mathrm{CNa}^{+}$ & 8 & MTHPA & 500 & 25 & 2 & 25 & 3 & 3.58 & 0.79 & 10.54 \\
\hline BC5 & 20 & C15 & 3 & IPDA & 200 & 25 & 2 & 45 & 1 & 38.77 & 0.66 & 31.77 \\
\hline BC6 & 60 & $\mathrm{CNa}^{+}$ & 5 & IPDA & 500 & 80 & 2 & 45 & 1 & 4.18 & 0.19 & 12.41 \\
\hline BC7 & 80 & C15 & 8 & IPDA & 500 & 80 & 1 & 25 & 1 & 0.55 & 0.10 & -5.59 \\
\hline BC8 & 0 & C10A & 3 & IPDA & 200 & 80 & 2 & 45 & 3 & 41.37 & 4.14 & 32.22 \\
\hline BC9 & 80 & C93A & 1 & IPDA & 500 & 25 & 2 & 45 & 3 & 0.56 & 0.17 & -6.22 \\
\hline BC10 & 80 & C10A & 5 & MTHPA & 200 & 25 & 2 & 25 & 1 & 1.11 & 0.36 & -0.03 \\
\hline BC11 & 20 & C10A & 1 & MTHPA & 500 & 80 & 1 & 45 & 1 & 20.82 & 2.59 & 26.18 \\
\hline BC12 & 60 & C15 & 1 & MTHPA & 200 & 80 & 2 & 25 & 3 & 21.34 & 5.33 & 25.92 \\
\hline BC13 & 60 & C10A & 8 & IPDA & 500 & 25 & 1 & 25 & 3 & 3.05 & 0.58 & 9.33 \\
\hline BC14 & 80 & $\mathrm{CNa}^{+}$ & 3 & MTHPA & 200 & 80 & 1 & 45 & 3 & 0.31 & 0.09 & -11.31 \\
\hline BC15 & 20 & C93A & 5 & IPDA & 200 & 80 & 1 & 25 & 3 & 32.52 & 1.19 & 30.23 \\
\hline BC16 & 60 & C93A & 3 & MTHPA & 200 & 25 & 1 & 45 & 1 & 9.09 & 3.37 & 17.89 \\
\hline
\end{tabular}


Table 3. Confirmation test results based on the preferred combination of factors for bioepoxy/clay nanocomposites

\begin{tabular}{|c|c|c|c|c|c|}
\hline $\begin{array}{l}\text { Output } \\
\text { responses }\end{array}$ & Formulation & $\begin{array}{l}\text { Confirmation } \\
\text { values (S/N } \\
\text { ratio) } \\
\text { (dB) }\end{array}$ & $\begin{array}{c}\text { C.I of } \\
\text { confirmation } \\
\text { test at } 95 \%\end{array}$ & $\begin{array}{c}\text { Predicted } \\
\text { value } \\
\text { (S/N } \\
\text { ratio) } \\
\text { (dB) }\end{array}$ & $\begin{array}{c}\text { C.I of } \\
\text { predicted } \\
\text { value at } \\
95 \%\end{array}$ \\
\hline Tensile & $\mathrm{A}_{1} \mathrm{~B}_{3} \mathrm{C}_{1} \mathrm{D}_{1} \mathrm{E}_{1} \mathrm{~F}_{1} \mathrm{G}_{1} \mathrm{H}_{2} \mathrm{I}_{1}$ & 35.42 & \pm 4.64 & 36.64 & \pm 1.55 \\
\hline strength & $\mathrm{A}_{2} \mathrm{~B}_{3} \mathrm{C}_{1} \mathrm{D}_{1} \mathrm{E}_{1} \mathrm{~F}_{1} \mathrm{G}_{1} \mathrm{H}_{2} \mathrm{I}_{1}$ & 29.91 & \pm 4.64 & 32.77 & \pm 1.55 \\
\hline
\end{tabular}

